\title{
An Optically Powered Radio over Fiber Remote Unit using Wavelength Division Multiplexing
}

\author{
D. Wake and N.J. Gomes \\ Department of Electronics \\ University of Kent \\ Canterbury, UK \\ d.wake@kent.ac.uk
}

\author{
C. Lethien, C. Sion and J.-P. Vilcot \\ IEMN \\ Université des Sciences et Technologies de Lille \\ Villeneuve d'Ascq, France \\ jean-pierre.vilcot@iemn.univ-lille1.fr
}

\begin{abstract}
Power over fiber and radio over fiber transmission have been combined in a single optical fiber using wavelength division multiplexing for the first time. It is shown that there is no impairment to the radio over fiber transmission performance from the power transmission link. There is however a power penalty caused by the insertion losses of the multiplexer and demultiplexer and potentially a further insertion loss depending on the type of transmission fiber used.
\end{abstract}

\section{INTRODUCTION}

The combination of power over fiber and radio over fiber to achieve optically-powered remote radio units has been proposed and experimentally demonstrated previously [1]. There it was concluded that optical powering was a feasible technique for many radio over fiber applications, especially in-building distributed antenna systems in situations where providing remote electrical power outlets is impractical, expensive or hazardous. Examples of where this would be useful include high voltage environments in electricity substations and in petrochemical plants where sparking may cause explosions. Radio over fiber is widely acknowledged as an excellent technique for simplifying the remote units required at antenna sites for wireless communications systems [2] and the use of power over fiber takes this simplification process a stage further by removing the need for electrical outlets at the antenna sites.

Separate optical fibers were used for optical power transmission and for radio signal transmission in [1], so that each fiber type could be optimized for its intended use. For power transmission, the fiber had a core diameter of $62.5 \mu \mathrm{m}$ (the largest core diameter in common use for in-building data networks), whereas for radio signal transmission the fiber had a core diameter of $50 \mu \mathrm{m}$ (high bandwidth fiber, optimized for short wavelength optical sources). In this paper we investigate the use of wavelength division multiplexing to achieve optical power transmission and radio signal transmission over a single fiber.

This work was partially supported by the European Union projects "EXTRACTT" (ERDF funded) and "ISIS" (IST Framework Programme 6).

\section{COMPONENT SELECTION}

\section{A. Power Laser and Photovoltaic Converter}

High power semiconductor lasers are available commercially with a variety of wavelengths and powers. The lasers with the highest output powers are multiple transverse mode devices with wide active layer widths. The available optical power scales with active layer width: for example, the JDSU 2300 series of high power lasers at $810 \mathrm{~nm}$ wavelength provide approximately $1 \mathrm{~W}$ of power per $100 \mu \mathrm{m}$ of active layer width [3]. Some fiber-coupled lasers provide even higher levels of power: for example, the JDSU 2486-L3 series lasers provide up to $2 \mathrm{~W}$ into a $60 \mu \mathrm{m}$ fiber at $830 \mathrm{~nm}$ [4] and the JDSU 2495-L3 series lasers provide up to $4 \mathrm{~W}$ at $808 \mathrm{~nm}$ into a $105 \mu \mathrm{m}$ fiber [5]. The work in [1] used a JDSU power laser with a fiber-coupled output of up to $2 \mathrm{~W}$ into $62.5 \mu \mathrm{m}$ fiber, chosen as a compromise between the need for high levels of optical power and compatibility with standard fiber types used for in-building data networks. This work uses the same laser for the same reasons. The wavelength of this laser is $834 \mathrm{~nm}$, which was chosen to be compatible with the PPC-4E from JDSU, the only fibercoupled photovoltaic converter that is commercially available to the authors' knowledge. The PPC-4E is also compatible with $62.5 \mu \mathrm{m}$ core diameter fiber.

\section{B. Transmission Fiber}

The transmission fiber should be multimode to accommodate the high levels of optical power provided by the high power laser. Multimode fiber dominates the inbuilding data network installed base [6]; it is clearly available and useful for deploying systems such as that described here for reasons of convenience and cost. This installed base multimode fiber has a core diameter of either $50 \mu \mathrm{m}$ or 62.5 $\mu \mathrm{m}$, with roughly equal predominance worldwide. The 
$62.5 \mu \mathrm{m}$ core diameter fiber would be the obvious choice to use in this work since it is compatible with the choice of high power laser. However, there are potential deployment scenarios where, for example, only $50 \mu \mathrm{m}$ fiber might be available for use. Furthermore, it is instructive to analyze the power penalty involved when using a transition from $62.5 \mu \mathrm{m}$ fiber to $50 \mu \mathrm{m}$ fiber, especially when a multimode laser is used as the optical power source. This transition penalty can vary from $0 \mathrm{~dB}$ to around $4 \mathrm{~dB}$ depending on the type of optical source [7]. From a signal transmission perspective, the over-filled launch bandwidth of $62.5 \mu \mathrm{m}$ fiber is less than that of $50 \mu \mathrm{m}$ fiber, but the actual bandwidth of each fiber type is very similar when using laser sources. It has been shown previously that multimode fiber with low over-filled launch bandwidth can have a good response beyond this bandwidth if a restricted number of modes are excited in the fiber during launch $[8,9]$. Therefore, a transmission fiber with a core diameter of $50 \mu \mathrm{m}$ was chosen for this work, allowing us to analyze the transition penalty problem.

\section{Signal Laser and Photodiode}

Most radio over fiber systems operate at a wavelength of $1310 \mathrm{~nm}$ using either Fabry-Perot (FP) or distributed feedback (DFB) lasers and InGaAs pin photodiodes. This wavelength is chosen because low cost components with good analog performance are available from a number of suppliers. The work in [9] used both FP and DFB lasers with a wavelength of $1310 \mathrm{~nm}$ and showed that good radio over fiber performance was achievable using fiber with a $50 \mu \mathrm{m}$ core diameter. The choice of laser used for this work was a $1310 \mathrm{~nm}$ FP device and the photodiode was a conventional InGaAs pin device in a receptacle package that was compatible with multimode fiber.

\section{WDM multiplexer and demultiplexer}

The wavelengths of $834 \mathrm{~nm}$ and $1310 \mathrm{~nm}$ and fiber core diameter of $50 \mu \mathrm{m}$ dictate the main specifications of the wavelength division multiplexer used. Additional important requirements are:

i. power path insertion loss: must be low enough such that power laser requirements are not unreasonably high;

ii. signal path isolation: must be high enough such that the power light does not significantly increase the noise at the output of the signal photodiode

iii. power handling: must be high enough to enable adequate power to be provided for the remote unit components.

Fortunately, there are many WDM components that can meet these requirements.

\section{EXPERIMENTAL SYSTEM LAYOUT}

The layout of the constructed experimental WDM transmission system is shown in Fig. 1. The aim of the experiment was to investigate the impact of using WDM to

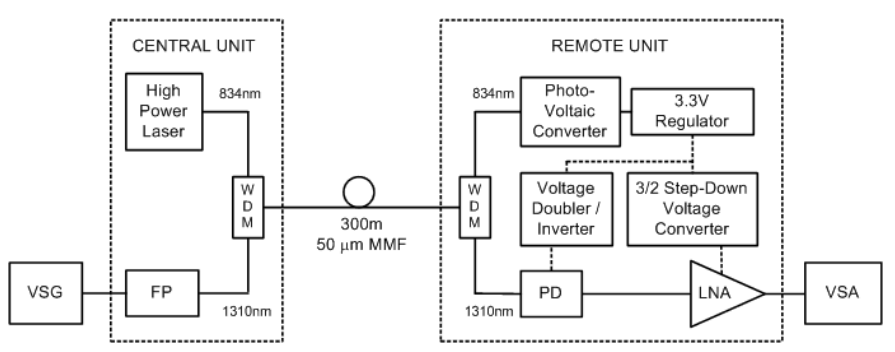

Figure 1. Experimental system layout.

combine signal and power over a single fiber; thus, the radio over fiber part was kept relatively simple (a unidirectional link with a post RF amplifier). The central unit consisted of a high power laser, signal laser $(1 \mathrm{~mW}$ at $1310 \mathrm{~nm}$ into single mode fiber) and WDM multiplexer (a thin-film micro-optic device with insertion loss of $0.3 \mathrm{~dB}$ at $834 \mathrm{~nm}$ and $0.2 \mathrm{~dB}$ at $1310 \mathrm{~nm}$ ).

The fiber reel consisted of $300 \mathrm{~m}$ of OM3 multimode fiber with a core diameter of $50 \mu \mathrm{m}$ and insertion loss of $0.7 \mathrm{~dB}$ at $834 \mathrm{~nm}$ and $0.1 \mathrm{~dB}$ at $1310 \mathrm{~nm}$. The relative response of this reel was $-1.2 \mathrm{~dB}$ at $1310 \mathrm{~nm}$ and $2.5 \mathrm{GHz}$. The fiber length chosen for this work is representative of a real deployment scenario since around $90 \%$ of the worldwide installed base of in-building multimode fiber is below this length [6].

The remote unit contained a WDM demultiplexer, photovoltaic converter, signal photodiode, RF amplifier, and power supply board containing a voltage regulator and voltage converters to provide power for the amplifier and photodiode [1]. The demultiplexer was the same type of device as the central unit multiplexer and had an insertion loss of $0.2 \mathrm{~dB}$ at $834 \mathrm{~nm}$ and $0.2 \mathrm{~dB}$ at $1310 \mathrm{~nm}$. The isolation of this device was $46 \mathrm{~dB}$ for power light leakage into the signal path and $23 \mathrm{~dB}$ for signal light leakage into the power path. Power light leakage into the signal path is of great concern for a system such as this since we are dealing with very high power levels; any light leakage will increase the photocurrent, generating excess noise. However, with an isolation of $46 \mathrm{~dB}$, there is no discernable increase in signal photocurrent as a result of using the optical power supply.

The remote unit amplifier was constructed using an Avago Technologies ATF-55143 transistor [10]. It was designed for $2.2 \mathrm{~V}$ operation, with a gain of $15 \mathrm{~dB}$ and a $\mathrm{P} 1 \mathrm{~dB}$ of $+7 \mathrm{dBm}$ at a frequency of $2.5 \mathrm{GHz}$. The power consumption of the amplifier was $20 \mathrm{~mW}(2.2 \mathrm{~V}$ and $9 \mathrm{~mA})$ and the power consumption of the signal photodiode was $5 \mathrm{~mW}(-6.6 \mathrm{~V}$ and $0.75 \mathrm{~mA}$ ). The power supply (voltage regulator and converters) had an overall efficiency of $82 \%$, which meant that the photovoltaic converter had to provide an electrical output power of $30 \mathrm{~mW}$. The photovoltaic converter provided a $4 \mathrm{~V}$ output with an optical to electrical conversion efficiency of $50 \%$, thus an optical power of $60 \mathrm{~mW}$ was required at its input. The transition from $62.5 \mu \mathrm{m}$ to $50 \mu \mathrm{m}$ core diameter fiber between the power laser and the WDM multiplexer resulted in an additional optical loss of $2 \mathrm{~dB}$. 
TABLE I. POWER BUDGET FOR REMOTE POWERING

\begin{tabular}{|l|c|}
\hline \multicolumn{2}{|c|}{ Remote Unit Electrical Power } \\
\hline Power required for PD and amplifier & $25 \mathrm{~mW}$ \\
\hline Power supply efficiency & $82 \%$ \\
\hline Total electrical power required & $30 \mathrm{~mW}$ \\
\hline \multicolumn{2}{|c|}{ Remote Unit Photovoltaic converter } \\
\hline Efficiency Fiber Losses for Power Link \\
\hline Required optical power & $50 \%$ \\
\hline \multicolumn{2}{|c|}{ Central Unit Power Laser } \\
\hline $62.5 \mu \mathrm{mW}-50 \mu \mathrm{m}$ transition & $2 \mathrm{~dB}$ \\
\hline WDM multiplexer & $125 \mathrm{~mW}$ \\
\hline 300 m fiber reel & $0.3 \mathrm{~dB}$ \\
\hline WDM demultiplexer & $0.2 \mathrm{~dB}$ \\
\hline
\end{tabular}

This loss is similar to the loss experienced when using optical sources that excite most of the fiber modes, such as LEDs [7], and is expected here since the power laser has an active layer width spanning the entire core of the output fiber. The total optical loss in the power transmission path including the fiber and WDM multiplexer/demultiplexer losses was therefore $3.2 \mathrm{~dB}$. The power laser output was set to $125 \mathrm{~mW}$ in order to provide the required power at the photovoltaic converter. The power budget for the remote powering is presented in Table I.

The power handling limit of the WDM multiplexer was $300 \mathrm{~mW}$, well above the optical power level used here. This limit will restrict the power available for high performance remote units, but other WDM components are commercially available with higher power handling capabilities. A multiplexer with $500 \mathrm{~mW}$ of power handling capability would be sufficient to provide approximately $140 \mathrm{~mW}$ of electrical power for the remote unit, assuming losses and efficiencies similar to those encountered here. In [1] it was shown that this level of electrical power was sufficient for a remote unit with a laser, photodiode and several stages of amplification, including a downlink power amplifier with a P1dB of at least $+16 \mathrm{dBm}$. The signal path (FP laser, multiplexer, fiber reel, demultiplexer and photodiode) had a total RF insertion loss of $30 \mathrm{~dB}$ at $2.5 \mathrm{GHz}$. The post amplifier gain was $15 \mathrm{~dB}$ which gave an end-to-end RF loss of $15 \mathrm{~dB}$ between the signal generator and signal analyzer. Characterization of the signal path was made by measuring error vector magnitude as a function of input power to the laser. Both optical and electrical power supplies (a standard bench-top power supply in place of the photovoltaic converter) were used in order to verify that there was no penalty associated with using the optical supply.

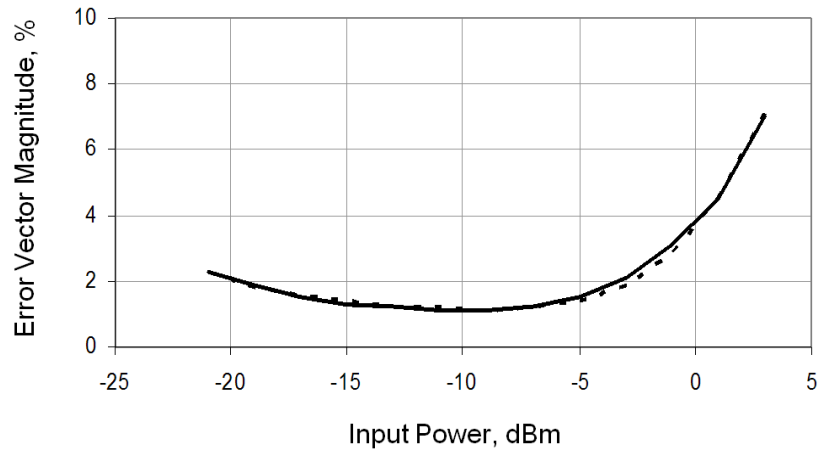

Figure 2. Error vector magnitude as a function of input power for optical (solid line) and electrical (dashed line) power supplies.

\section{TRANSMISSION MEASUREMENT RESULTS}

Error vector magnitude was measured as a function of input power to the signal laser and the results are given in Fig. 2 for both optical and electrical power supplies. Transmission was at $2.5 \mathrm{GHz}$ using a 64-QAM, OFDM signal with a symbol rate of $9 \mathrm{Ms} / \mathrm{s}$. These are the most demanding modulation and symbol rate parameters used in the IEEE802.11g wireless local area networking standard [10]. The EVM curve follows the expected shape; at low input power the EVM is high due to reduced signal to noise ratio and at high input power the EVM is high due to increased distortion from the laser and RF amplifier. At the optimum input power, the EVM is $1.1 \%$ which is very low compared to the maximum allowed in the IEEE802.11g specification of $5.6 \%$. The transmission performance of the signal path is therefore of high quality. The most important point to note from Fig. 2 however is that there is no significant difference between the EVM curves for each type of power supply. This is because the isolation of the WDM demultiplexer is sufficient to avoid any additional noise at the output of the signal photodiode. This was verified by performing separate noise measurements at 2.5 $\mathrm{GHz}$. A noise power of $-119 \mathrm{dBm} / \mathrm{Hz}$ was measured for both types of power supply. For the present experimental arrangement, the additional photocurrent is calculated to be only $1.5 \mu \mathrm{A}$, which is insignificant compared to the signal photocurrent of $0.75 \mathrm{~mA}$.

\section{CONCLUSION}

Wavelength division multiplexing has been used to combine signal and power transmission on a single fiber to provide an optically powered radio over fiber remote unit. The isolation of the thin-film micro-optic WDM demultiplexer used is found to be high enough to ensure that there is no impact on signal transmission performance (at the wavelengths chosen). The only impact is the higher optical power requirements for the high power laser, due to multiplexer and demultiplexer losses (a total of $0.5 \mathrm{~dB}$ in this case) and any additional loss incurred if a smaller core diameter transmission fiber is chosen compared to that of the power laser output fiber. In 
the case described here (with a $62.5 \mu \mathrm{m} / 50 \mu \mathrm{m}$ fiber transition), an additional $2 \mathrm{~dB}$ power penalty is observed. With similar losses and efficiencies to those measured in this work, commercially available WDM multiplexers with at least $500 \mathrm{~mW}$ power handling capability would be able to provide approximately $140 \mathrm{~mW}$ of electrical power for the remote unit.

\section{ACKNOWLEDGMENT}

The authors thank Vincent Thirion for his help with constructing the optical modules and Anthony Nkansah for his help with some of the measurements.

\section{REFERENCES}

[1] D. Wake, A. Nkansah and N.J. Gomes, "Optical Powering of Remote Units for Radio over Fiber Links", IEEE International Topical Meeting on Microwave Photonics, pp. 29-32, Oct. 2007.
[2] A. Arredondo, D.M. Cutrer, J.B Georges, and K.Y. Lau, "Techniques for improving in-building radio coverage using fiber-fed distributed antenna networks", IEEE Vehicular Technology Conference, vol.3, pp. 1540-1543, May 1996.

[3] JSDU Commercial Lasers Datasheet, 2300 series, www.jdsu.com, 2007.

[4] JSDU Commercial Lasers Datasheet, 2486-L3 series, 2007.

[5] JSDU Commercial Lasers Datasheet, 2495-L3 series, 2007.

[6] A. Flatman, "In-premises optical fiber installed base analysis to 2007," presented at the IEEE 802.3 10GBE over FDDI-Grade Fiber Study Group, Orlando, FL, Mar. 2004.

[7] Multimode Fiber Compatibility Application Note, Corning Inc., www.corning.com/opticalfiber, 2005.

[8] L. Raddatz, I.H. White, D.G. Cunningham and C. Nowell, "Influence of restricted mode excitation on bandwidth of multimode fiber links", IEEE Photon. Technol. Lett., vol. 10, pp. 534-536, Apr. 1998.

[9] D. Wake, S. Dupont, C. Lethien and J.-P. Vilcot, "Radio frequency transmission of 32-QAM signals over multimode fiber for distributed antenna system applications," Electron. Lett., vol. 37, pp. 1087-1089, Aug. 2001.

[10] Avago Technologies Technical Datasheet, ATF-54143, www.avagotech.com, 2003.

[11] IEEE Std $802.11 \mathrm{~g}-2003$. 